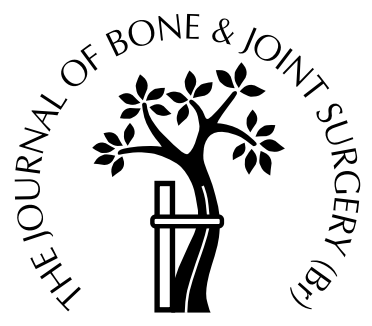

\title{
The results of endoprosthetic replacement for tumours of the distal humerus
}

\author{
A. Kulkarni, F. Fiorenza, R. J. Grimer, S. R. Carter, R. M. Tillman \\ From the Royal Orthopaedic Hospital, Birmingham, England
}

T en patients underwent endoprosthetic replacement of the distal humerus for bone tumours over a period of 30 years. There were eight primary and two secondary tumours in four men and six women with a mean age of 47.5 years (15 to 76). The mean follow-up was eight years (9 months to 31 years). Four patients required further surgery, three having revision for aseptic loosening; two of these and one other later needing a rebushing. There were no cases of postoperative nerve palsy, infection, local recurrence or mechanical failure of the implant. Four patients died from their disease, all with the prosthesis functioning satisfactorily. At follow-up the mean flexion deformity of the elbow was $15^{\circ}(0$ to 35$)$ and the mean range of flexion was $115^{\circ}(110$ to 135$)$. The functional results showed a mean Toronto extremity salvage score of $73 \%$ of normal. Endoprosthetic replacement of the distal humerus and elbow is a satisfactory method of treating these rare tumours.

J Bone Joint Surg [Br] 2003;85-B:240-3.

Received 8 March 2002; Accepted after revision 26 September 2002.

Only $1 \%$ of primary bone tumours arise in the distal humerus. Reconstruction after excision is technically difficult. Neither an excision arthroplasty of the elbow nor an arthrodesis is possible because of the large amount of bone which is removed. Allograft reconstruction and hemiarthroplasty are rarely undertaken and have an unpredictable outcome. ${ }^{1-3}$ Endoprosthetic replacement may be used to reconstruct the elbow and distal humerus after excision of a tumour and there are two previous reports of this method of treatment with a mean follow-up of 4.5 and 2.5 years, respectively. ${ }^{4,5}$ In one series, replacement had also been used for patients with

A. Kulkarni, MRCS, Research Fellow in Oncology

F. Fiorenza, FRCS, Senior Oncology Fellow

R. J. Grimer, FRCS, Consultant Orthopaedic Oncologist

S. R. Carter, FRCS, Consultant Orthopaedic Oncologist

R. M. Tillman, FRCS, Consultant Orthopaedic Oncologist

Oncology Service, The Royal Orthopaedic Hospital, Bristol Road South, Birmingham B31 2AP, UK.

Correspondence should be sent to Mr R. J. Grimer.

(C)2003 British Editorial Society of Bone and Joint Surgery doi.10.1302/0301-620X.85B2.13524\$2.00 benign or degenerative conditions. Both series reported a low incidence of complications at short-term follow-up.

We have reviewed our experience of endoprosthetic replacement of the distal humerus for bone tumours and assessed the functional outcome and complications.

\section{Patients and Methods}

Between 1970 and 2001 we carried out endoprosthetic replacement of the distal humerus in ten patients after resection of a bone tumour. Eight had primary and two secondary tumours. Details of the patients and their treatment are shown in Table I. There were four men and six women with a mean age of 47.5 years (15 to 76 ).

The decision to use an endoprosthetic replacement followed full staging and biopsy of the tumour. We assessed the extent of the tumour using radiography, CT and, more recently, MRI. Amputation was usually required if the tumour had an extensive soft-tissue component or if it involved the elbow or the neurovascular bundle. Chemotherapy was given if indicated.

All the endoprostheses were based on the Stanmore elbow replacement (Stanmore Implants Worldwide Ltd, Centre for Biomedical Engineering, Stanmore, UK) which is a constrained, hinged prosthesis made of cobalt chrome, but extended with appropriate titanium shafts and intramedullary stems. ${ }^{6}$

The operative technique involved excision of the tumour through an anterior Henry's approach, extended distally below the elbow anterolaterally. ${ }^{7}$ After dividing the humerus proximally and mobilising the tumour, retaining a cuff of normal tissue, we opened the elbow and, after identifying and preserving the ulnar nerve, removed the distal humerus. The hinged prosthesis was inserted into the ulna and humerus with cement. The two parts of the prosthesis were then connected using high-density polyethylene (HDPE) bushes. Active postoperative movements were started when the wound had healed and passive extension was encouraged at an early stage. All patients underwent regular clinical and radiological review. For functional analysis we used the Toronto extremity salvage (TES) score. 8,9 This assesses 32 functions with a score from 1 to 5 for each activity. The total score is expressed as a percentage. The range of movement was also assessed. 
Table I. Details of the ten patients, their tumours and the outcome after endoprosthetic replacement

\begin{tabular}{|c|c|c|c|c|c|c|c|}
\hline Case & Diagnosis & Age (yrs) & Gender & $\begin{array}{l}\text { Prosthesis survival to } \\
\text { revision or death (mths) }\end{array}$ & $\begin{array}{l}\text { Patient } \\
\text { survival }\end{array}$ & $\begin{array}{l}\text { Rebushing } \\
\text { (mths) }\end{array}$ & $\begin{array}{l}\text { TESS score } \\
(\%)\end{array}$ \\
\hline 1 & Osteosarcoma & 56 & $\mathrm{M}$ & 71 & 71 died & & \\
\hline 2 & Liposarcoma & 59 & $\mathrm{~F}$ & 29 & 29 died & & \\
\hline 3 & Leiomyosarcoma & 46 & M & 12 & 12 died & & \\
\hline 4 & Plasmacytoma & 76 & M & 28 & 28 alive & & 83 \\
\hline 5 & Plasmacytoma & 56 & $\mathrm{~F}$ & 5 & 9 alive & & 58 \\
\hline 6 & Pleomorphic sarcoma & 39 & M & 142 & 142 alive & 113 & 90 \\
\hline 7 & Giant-cell tumour & 51 & $\mathrm{~F}$ & 366 & 372 alive & & 29 \\
\hline 8 & Osteosarcoma & 15 & $\mathrm{~F}$ & 48 & 89 alive & 78 & 93 \\
\hline 9 & Renal metastasis & 48 & $\mathrm{~F}$ & 56 & 190 alive & 62 & 85 \\
\hline 10 & Breast metastasis & 29 & $\mathrm{~F}$ & 29 & 29 died & & \\
\hline
\end{tabular}

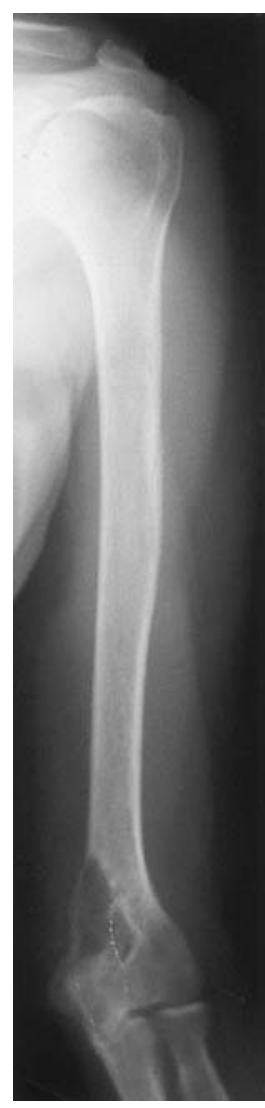

Fig. 1a

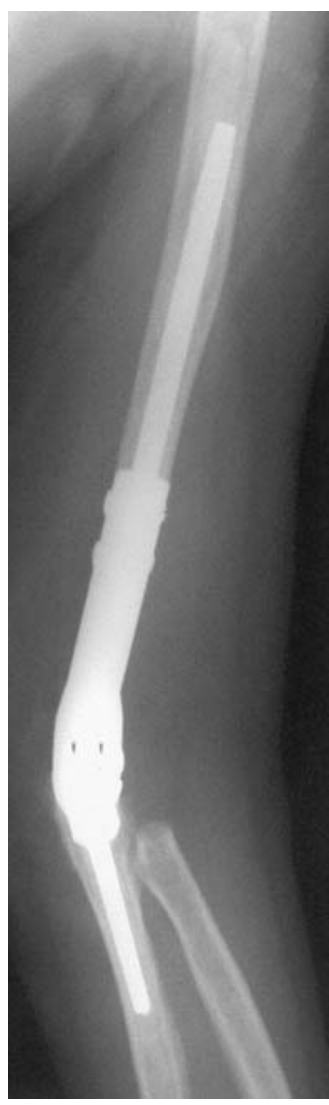

Fig. 1b

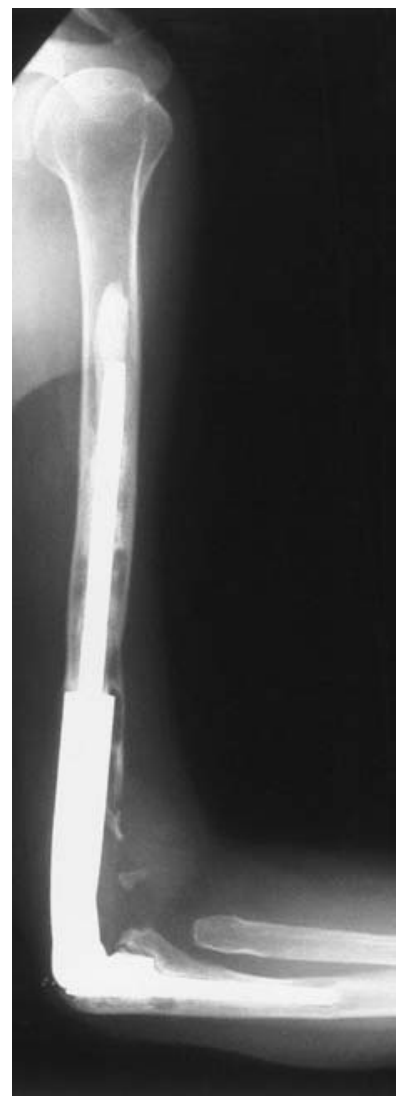

Fig. 1c

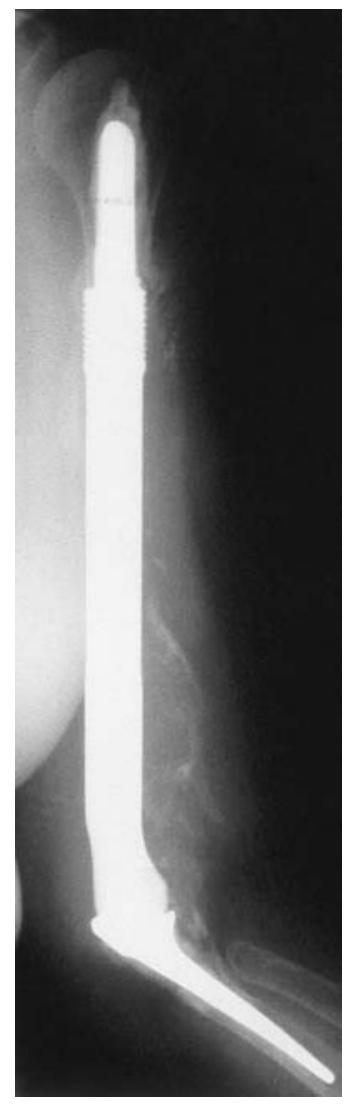

Fig. 1d

Radiographs showing a) the preoperative AP view of the humerus and elbow of a patient with a giant-cell tumour, b) the AP view 18 years after endoprosthetic replacement, c) the lateral view 30 years after endoprosthetic replacement, and d) the AP view after revision of the endoprosthetic replacement.

\section{Results}

The first operation was carried out in 1970 and this patient is alive and free from the disease. Four patients died from metastatic disease between 12 and 71 months after operation without evidence of loosening, infection or local recurrence. Overall, no operation was complicated by local recurrence, infection or nerve palsy.

Three patients underwent revision of the prosthesis at 48, 56 and 366 months for aseptic loosening of the humeral component. Two of these and one other required subse- quent replacement of the HDPE bushes. There have been no complications requiring revision of the ulnar component.

The mean TES score was $73 \%$ (29 to 93). The activities which the patients found to be easy (TES score $>4.5$ of 5) were brushing the hair, drinking from a glass, putting on cosmetics or shaving, picking up small items, turning a key in a lock, doing light household chores and socialising with friends. The activities which proved difficult (TES score $<3$ of 5) were gardening and lifting a box to an overhead shelf. Only one of the surviving patients used regular analgesics. 


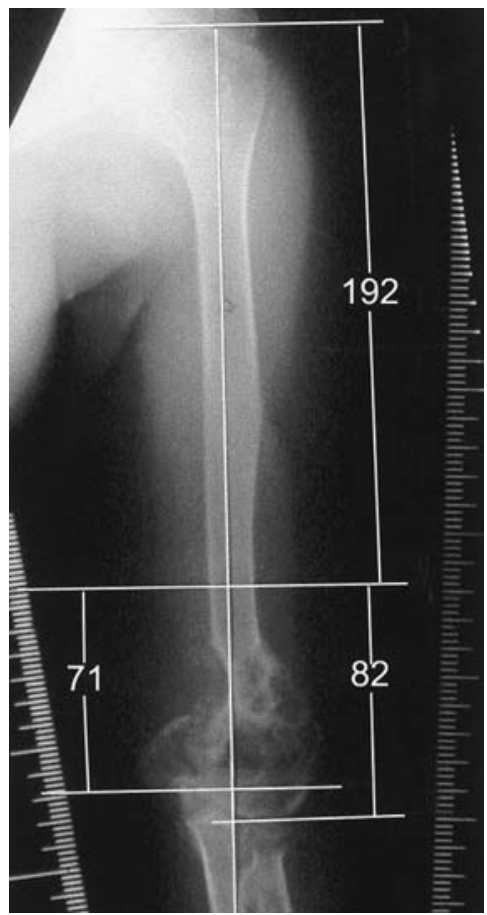

Fig. 2a

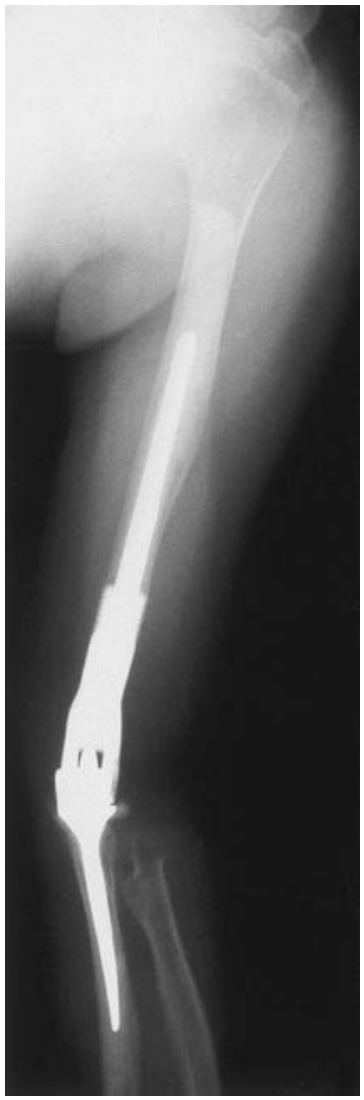

Fig. 2c

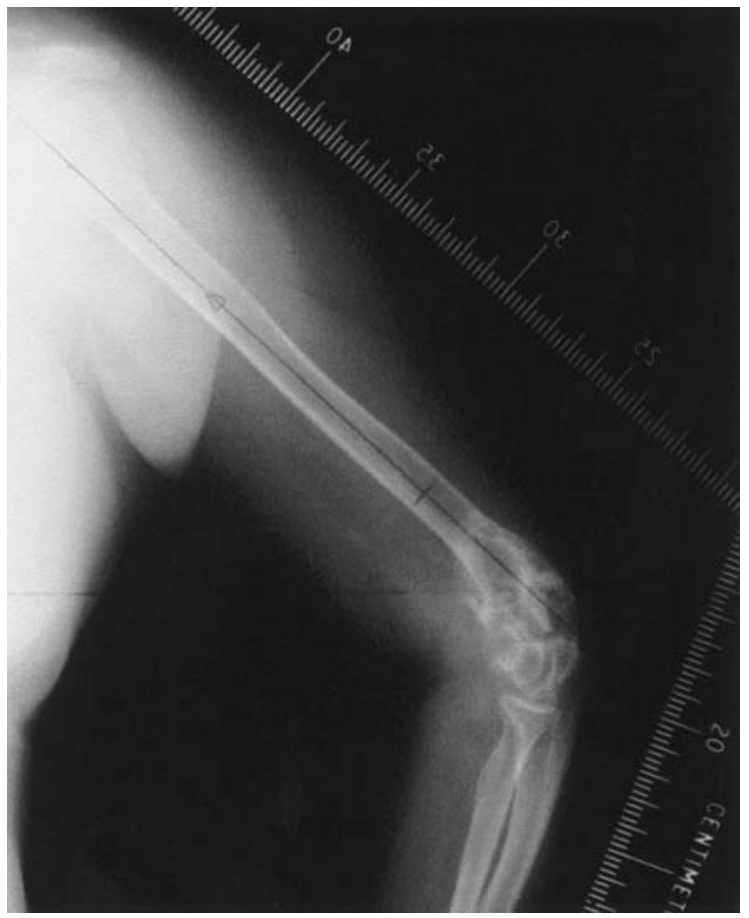

Fig. 2b

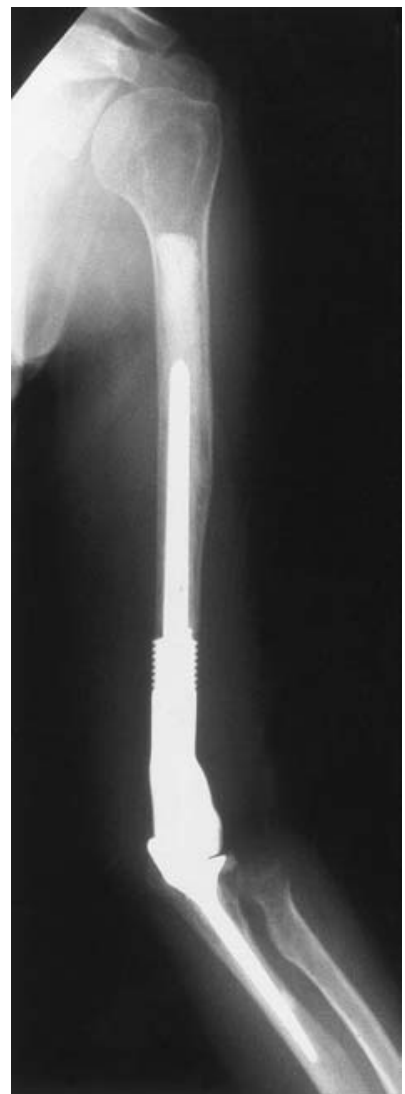

Fig. 2d

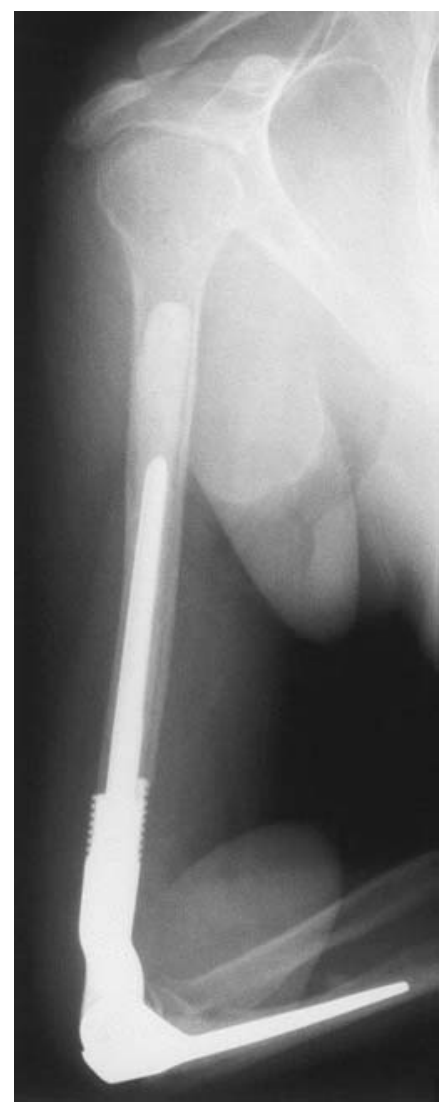

Fig. 2e

Radiographs showing a) the preoperative AP view of the humerus and elbow of 56-year-old patient with a plasmacytoma and b) the lateral, c) the AP, d) the lateral in extension and e) the lateral in flexion views six months after endoprosthetic replacement. 
At the last follow-up the mean fixed flexion deformity of the elbow was $15^{\circ}$ (0 to 35) and the mean range of flexion was $115^{\circ}$ (110 to 135 ) (Figs 1 and 2).

\section{Discussion}

Our small series indicates how rarely bone tumours affect the distal humerus. During the past 30 years only 17 of 1743 primary bone tumours presenting to our unit have arisen in the distal humerus. This represents less than $1 \%$. The need to reconstruct the distal humerus for primary bone tumours is so rare that it is not mentioned in major text-books. ${ }^{10}$

Endoprosthetic replacement of the distal humerus is one way of reconstructing the elbow after excision of a bone tumour. The advantages are immediate stability and the early return of function. The potential disadvantages include the likelihood of failure of the prosthesis at some stage either by wear of the bushes, loosening, infection or fracture. Prolonged follow-up is necessary to identify the incidence of these risks and whether function deteriorates with time. There are few reports of alternative methods of reconstruction. Dean et $\mathrm{al}^{3}$ described the use of allografts to reconstruct a variety of defects of the distal humerus in 23 patients including one with a tumour. There were complications in 16 patients which included three cases of deep infection, six of instability of the elbow, four of palsy of the radial nerve and seven of nonunion. They concluded that: "This operation is not recommended for routine use and is viewed as a salvage procedure". Arthrodesis of the elbow is impractical unless a bone graft is used and this will have all the deficiencies of the above procedure combined with a stiff elbow.

Ross et $\mathrm{al}^{4}$ described four patients who had had an endoprosthesis of the distal humerus for a tumour as a part of a series of distal and total humeral replacements for a variety of causes. The mean follow-up was 5.8 years. The rate of local recurrence, infection and aseptic loosening were all $11.5 \%$ at short-term follow-up.

Sperling et $\mathrm{al}^{5}$ described 13 patients with tumours involving the elbow treated by a standard Coonrad (semiconstrained) prosthesis between 1980 and 1993. There were seven primary and six secondary tumours. The mean range of flexion of the elbow improved from $29^{\circ}$ to $73^{\circ}$ and the pain score decreased from 3.6 to 2.0 on a scale with 4 as the maximum. There were complications in six patients. Three of the six patients with a secondary tumour developed a local recurrence, one of which needed amputation. Two patients had a nerve palsy and one had heterotopic ossification.

As far as we are aware the hemiarthroplasty which was described by Shifrin and Johnson ${ }^{11}$ has not been used in patients with a tumour.

In our study, there was no postoperative infection, nerve palsy or local recurrence and in no patient was amputation required. There were six further operations in four patients, three revisions for aseptic loosening and three rebushings. The rebushings involve simple replacement of the HDPE bushes, usually carried out through a separate posterior approach. There were no complications after this procedure. The bushes on the first patient to have an endoprosthesis of the distal humerus inserted, in 1970, were inspected when the prosthesis was revised and were in good condition. The three revisions were carried out at 4, 4.5 and 30 years after operation, all for loosening of the humeral component. The use of hydroxyapatite collars in modern prostheses may reduce the incidence of loosening. ${ }^{12}$

The functional outcome after elbow replacement, using the Mayo score, has been reported by many authors. ${ }^{13} \mathrm{We}$ chose to use the TES score, since it is a functional score which has been validated for tumour surgery. We would not expect a tumour endoprosthesis to allow such good function as a conventional elbow replacement in which the soft tissues and ligaments are largely preserved, unlike in resections for tumour in which all the ligaments and much other soft tissue are removed.

Our small series shows that replacement of the distal humerus for tumours using a hinged prosthesis is successful, restoring and maintaining function with a low incidence of complications. Satisfactory function was also maintained in those patients who required a revision procedure or rebushing.

We would like to thank Miss Nikki Allwood, research secretary at The Royal Orthopaedic Hospital, Birmingham for her contribution in preparing this paper.

No benefits in any form have been received or will be received from a commercial party related directly or indirectly to the subject of this article.

\section{References}

1. Urbaniak JR, Black KE. Cadaveric elbow allografts: a six year experience. Clin Orthop 1985;197:131-40.

2. Capanna R, Campanacci D, Del Ben M, Masetti C, Donati, D. Total elbow replacement with osteoarticular allografts. Limb Salvage Current Trends: Procs 7th International Symposium 1993;277-282.

3. Dean GS, Hollinger EH $4^{\text {th }}$, Urbaniak JR. Elbow allograft for reconstruction of the elbow with massive bone loss: long term results. Clin Orthop 1997;341:12-22.

4. Ross AC, Sneath RS, Scales JT. Endoprosthetic replacement of the humerus and elbow joint. J Bone Joint Surg [Br] 1987;69-B:652-5.

5. Sperling JW, Pritchard DJ, Morrey BF. Total elbow arthroplasty after resection of tumours at the elbow. Clin Orthop 1999;367:256-61.

6. Johnson JR, Getty CJ, Lettin AW, Glasgow MM. The Stanmore total elbow replacement for rheumatoid arthritis. J Bone Joint Surg [Br] 1984;66-B:732-6.

7. Henry AK. Extensile exposure. Edinburgh: Churchill Livingstone, 1970.

8. Davis AM, Devlin M, Griffin AM, Wunder JS, Bell RS. Functional outcome in amputation versus limb sparing of patients with lower extremity sarcoma: a matched case-control study. Arch Phys Med Rehabil 1999;80:615-8.

9. Davis AM, Wright JG, Williams JI, et al. Development of a measure of physical function for patients with bone and soft tissue sarcoma. Qual Lif Res 1996;5:508-16.

10. Simon MA, Springfield D, eds. Surgery for bone and soft tissue tumours. Lippincott-Raven, Philadelphia, 1998.

11. Shifrin PG, Johnson DP. Elbow hemiarthroplasty with 20 year follow up study: a case report and literature review. Clin Orthop 1990;254:12833 .

12. Blunn GW, Briggs TW, Cannon SR, et al. Cementless fixation for primary segmental bone tumour endoprostheses. Clin Orthop 2000;372:223-30.

13. Morrey BF, An K-N, Chao EYS. Functional evaluation of the elbow. In: Morrey BF, ed. The elbow and its disorders. Philadelphia: WB Saunders, 1993:74-83. 